\title{
Religiones castreñas contra el estado
}

\section{Castreño religions against the State}

\author{
Alberto Santos Cancelas \\ Investigador independiente \\ albertosantoscancelas@hotmail.com
}

Fecha de recepción: 16-11-2018

Fecha de aceptación: 01-03-2019

\section{RESUMEN}

Nuestro conocimiento sobre las religiones protohistóricas se encuentra prejuiciado por categorías de pensamiento presentistas y el recurso a fuentes posteriores. Para lograr una caracterización mínima de la fenomenología de tales manifestaciones se propone una aproximación a partir de los materiales de la Edad del Hierro, con atención a los problemas y metodologías de la arqueología, que privilegie el estudio de casos particulares frente a la generalización céltica. A través del ejemplo de la cultura castreña, se examinará qué elementos constituyeron objeto de atención ritual y sobredimensión simbólica para una sociedad de la Edad del Hierro.

PALABRAS CLAVE: Cultura Castreña, Edad del Hierro, protohistoria, ritual, arqueología

\section{ABSTRACT}

Our knowledge of protohistoric religions is prejudiced by presentist ways of thinking and recourse to later sources. To achieve a minimum characterization of the phenomenology of such manifestations, I propose an approach based on Iron Age materials, being careful of the archaeological problems and methodologies, and favouring particular case studies rather than Celtic generalizations. Through the example of Castreño culture, I will examine which elements might have been the object of ritual attention and symbolic oversizing in an Iron Age society.

KEY WORDS: Castro culture, Iron Age, Protohistory, ritual, archaeology

\section{INTRODUCCIÓN: LAS RELIGIONES DESCONOCIDAS}

Ante la perspectiva de tener que trazar una semblanza de qué constituye "lo sagrado" para los pueblos paleohispánicos, uno se da cuenta de hasta qué punto la Edad del Hierro es un lugar desconocido. Debido al carácter ágrafo de la mayoría de estas culturas, se ha privilegiado en su estudio documentos que, por resultar más elocuentes para nosotros, poco 
tenían que ver con las religiones prerromanas (Santos Cancelas, 2016: 18), condicionando así su comprensión.

\subsection{Condicionantes}

La ciencia de las religiones ha privilegiado la fuente textual favoreciendo una aproximación filológica, que impone sobre pueblos ágrafos fenomenologías propias de pueblos con escritura. Aplicado a este caso, concede un mayor peso a los textos clásicos y la epigrafía votiva de época antigua, derivando en una lectura retrospectiva que subordina las fuentes materiales de la Edad del Hierro.

El recurso a documentos posteriores congela estas religiones en un "presente etnográfico" que entiende como característicos rasgos provocados por las interacciones asimétricas a través de las que fueron conocidas por pueblos con escritura (Fabian, 1983: 80-81). Aunque no existen las religiones puras, la alteración en las relaciones de poder locales que supuso el entanglement con Roma (Woolf 2011: passim) planteó un middle ground o third space (Santos Cancelas e.p.) al que las religiones indígenas tuvieron que dar respuesta. Tales manifestaciones son por ello reacciones a contextos históricos específicos, no el floruit de tendencias previas.

Este uso selectivo de fuentes deriva en gran medida de un celtismo que ha amplificado los prejuicios etnocéntricos de las fuentes clásicas, homogeneizando unas religiones de la Europa Occidental cuyo parecido es relativo. Estas posturas privilegian las similitudes frente a las diferencias, resultando en un esencialismo que difumina las complejas relaciones -interesadas y situacionales- entre cultura, identidad y religión. $\mathrm{Y}$ así, entiende como herencias estructurales representaciones que resultan de asumir una posición subalterna frente a agendas hegemónicas.

Se debe favorecer un recurso a los documentos de la Edad del Hierro que privilegie metodologías y problemáticas propias de la arqueología, para recuperar la dimensión histórica que el presente etnográfico ha eliminado, y matizar las lecturas generales a través del estudio de casos particulares, como el del noroeste peninsular. Al haberse definido su religión prerromana a través de rasgos provocados por el contacto con Roma, este ejemplo ilustra en qué medida nuestras expectativas han condicionado el análisis.

\subsection{La cultura castreña prerromana}

En una fecha que, con ciertos matices, se podría situar en el s. VII a. C. irá surgiendo en el Noroeste peninsular la llamada cultura castreña. Su principal característica es, precisamente, que el único tipo de asentamiento conocido es el castro, un recinto fortificado de escasas dimensiones. Pese a cierta variabilidad regional, no hay ningún tipo de jerarquización territorial ${ }^{1}$ : sin asentamientos secundarios, diferencias fundamentales en su tamaño, ni señal alguna de procesos de centralización hasta el s. Il a. C., un momento de múltiples cambios que se conoce como Hierro Final.

La configuración interna de los castros tampoco presenta diferencias sustanciales. En un espacio constreñido por afloramientos rocosos, se distribuyen cabañas, pétreas o de materiales perecederos. Desconocemos la configuración social de la unidad doméstica (Currás, 2014: 47), pero su relativa homogeneidad, unida a la inexistencia de una cultura material de prestigio, indica una ausencia de jerarquización social. Son grupos sin fuertes desigualdades de clase hasta el Hierro Final.

1 Aunque existen posturas que cuestionan esto, derivan de lecturas evolucionistas. No existen argumentos que justifiquen la existencia de jerarquización territorial anterior al s. II a. C., señal del cambio producido. 
Su elemento definitorio es la muralla, que puede ser pétrea o un simple talud de tierra. Además de un evidente papel defensivo, esta preestablecía un crecimiento limitado para el grupo, al no ser nunca rebasada (Sastre, 2011). Se trata por ello de asentamientos agrícolas que recurrieron a la escisión como medio para evitar el incremento del grupo. Cada comunidad se encierra en un territorio del que se apropiaba mediante el castro, generando un paisaje atomizado.

Las propuestas más aceptadas sobre su surgimiento (Parcero, 2007; González García, 2011; Parcero Criado, 2013) derivan de las teorías de Clastres (1984). Estas entienden el mundo castreño como una reacción contra la jerarquización social experimentada a finales del Bronce Final (siglos X-VIII a. C.). En paralelo a la irrupción del hierro, y el impacto precolonial en el sur peninsular, estas comunidades reaccionaron limitando su contacto, crecimiento y generación de excedentes (Sastre, 2008), para evitar la reaparición de marcadas desigualdades de clase. Se sugiere que la acumulación de poder se evitó a través de una fuerte competitividad guerrera entre individuos y grupos, que acabó siendo subvertida y ocasionando la reaparición de jerarquías, a causa del incremento de excedentes y un temprano contacto con navegantes mediterráneos.

Sin embargo, esto contradice las teorías de Clastres al presuponer que las propias características de grupos contrarios al estado pudieron favorecer la concentración de poder, o comenzar a producir excedentes, cuando se opone a sus dinámicas productivas. Y, por otro lado, se enfrenta a la ausencia de una panoplia que merezca tal nombre y sugiera la existencia de semejante competitividad ${ }^{2}$; que no se pueda hablar de comercio como tal hasta el s. Il a. C. (Currás 2014: 508, 614 y ss.); y el que ni grandes castros, ni iconografía, ni bienes de importación en cantidades destacables se generalicen hasta el contacto con Roma, una cultura de estado.

\section{RELIGIONES CASTREÑAS}

La diferencia entre los grupos prerromanos y ciertas comunidades que en Hierro Final dan muestras de una notable jerarquización se aprecia también en su registro ritual. Tanto es así, que quizás la propia naturaleza de las religiones prerromanas también fuera contraria al estado.

\subsection{Cambios de Hierro Inicial}

Uno de los hechos más llamativos de la cultura castreña es la desaparición de ritos muy arraigados en el Noroeste durante Bronce Final. La práctica de retirar armas en aguas (Ulla, Sil, Miño, Abelenda, etcétera), así como en hendiduras rocosas o cistas (Mourúas, Telhado), presenta la suficiente recurrencia y paralelos en otros contactos atlánticos como para asumir que se trató de gestos rituales (Santos Cancelas, 2017: 94-104, 114-118, 127 130). Y aunque las ocultaciones de orfebrería en rocas se han tendido a entender como depósitos de riqueza desde prejuicios presentistas (Brück y Fotijn, 2003), su frecuencia, aparición en lugares significados y supuesto consumo por parte de jefaturas atlánticas, indica posibles connotaciones rituales en su retirada.

No es extraño comprobar por ello que dos de los elementos que caracterizaron la definición de tales jefaturas desaparezcan en la ritualidad castreña. Tendría cierta lógica que las comunidades que reaccionan a la jerarquización previa desactivaran los elementos de poder simbólico en los que aquella se sustentó. Cabría entonces interrogarse por qué,

2 Al no ser grupos excedentarios, su presión territorial es limitada. Además, la competitividad por los recursos que sugiere González Ruibal (2006-07: 185-186) a través de casos como O Morrazo incluye asentamientos cuya ocupación no es necesariamente sincrónica. 
frente a este vacío, se sigue considerando el ejercicio de la guerra como característica de esta sociedad y su religión (García Quintela, 1999: 287 y ss.; González García, 2006), un aspecto en el que representaciones clásicas de la barbarie parecen ejercer una notable influencia.

No existe ningún depósito de armas cuya intencionalidad se pueda verificar con anterioridad a Hierro Final $^{3}$ más allá de dudas razonables. Aunque se defiende la existencia de armas desde los siglos VI y $\vee$ a. C., se trata de ejemplos descontextualizados a los que se asignó esta cronología en base a una hipótesis evolutiva (Ruíz Gálvez 1980; Quesada 1997: 197), como sería el caso de Couboeira, que encuentra paralelos formales en puñales de antenas hallados en niveles de siglos II y I a. C. Las únicas armas de Hierro Inicial suelen ser ejemplos arcaizantes, distantes de lo que se podría considerar una panoplia desarrollada. La ausencia de ritos guerreros se corresponde con una falta de énfasis en el ejercicio de la guerra, que hay que dejar de explicar como una deficiencia y entender como una característica: la importancia de la violencia en la forma específica de la guerra no era valorada por esta religión (Santos Cancelas, e.p.).

\subsection{Hachas de memoria}

Estas ausencias son elocuentes ante la posible continuidad de los depósitos de hachas típicos del Bronce Final. Aunque también se han tendido a entender de un modo estrictamente utilitario en relación con el intercambio de bronce, la enorme cantidad de conjuntos que han aparecido retirados en márgenes fluviales posibilita que fueran más bien ofrendas en relación con ese intercambio (Santos Cancelas, 2017: 110-114).

Su posición habitual carece de relación directa con contextos antrópicos, por lo que se datan en Bronce Final siguiendo criterios tipológicos, pese a la existencia de ejemplos en relación con contextos castreños. Aunque su hallazgo antiguo, deficiente publicación, o que no se consignase la relación con poblado, afecta a su valoración, estos ejemplos apuntan una posible circulación durante la Edad del Hierro similar a la de otros contextos atlánticos (Hingley, 2009).

El hallazgo de un hacha de bronce arcaica en Chao de Sanmartín (Blas Cortina, Villa Valdés, 2007) en una cista de un fondo de hogar apunta que, al menos en este periodo, se amortizaron como ofrendas votivas. Este sería también el caso de un ejemplar de hacha de talón y cuatro anillas aparecido en una unidad doméstica de Viladonga. Ambos ejemplos son de Hierro Final, momento en el que se da la difusión por el occidente peninsular de los llamados bronces votivos (Armada, García Vuelta, 2003), cuya iconografía imita la forma de hachas.

Estos fenómenos diferentes testimonian el uso votivo de hachas de talón y dos anillas de gran antigüedad, sumado a la aparición de útiles litúrgicos con formas de hacha en fechas posteriores al siglo II a. C. Si bien esto supone un cambio derivado del middle ground de este periodo, una serie de ejemplos indican que en cronología prerromana ciertas hachas pudieron tener también funciones votivas.

Se trata de una serie de casos dispersos de depósitos como Alcabre (Suárez Otero, 2007), hallado en un nivel anterior a una cabaña castreña. O conjuntos de hachas retirados cuidadosamente en inmediaciones de castros como Santa María de Paradela, Bardaos (Ladra, 2006), o Cabeiro (Carballo Arceo, Rey Castiñeiras, 2014). La nómina de hachas sin un contexto preciso aumenta con los ejemplos de Álava, Castrelo de Pelou, Collada, Larón, Pendía (Blas Cortina, 1983: 148), Anxeriz (Meijide Cameselle y Acuña Castroviejo,

3 Taramundí sería el único caso con una C-14 prerromana, pero su antigüedad la hace dudosa incluso para los propios arqueólogos (Fanjul Peraza y Marón, 2006: 114). 
1989: 19), e incluso otro posible caso de hachas retiradas bajo una vivienda en Montealegre (Santos Cancelas, 2017: 805-806). La mayoría han sido entendidos como restos de ocupaciones anteriores no verificadas, en base a la supuesta cronología de las hachas, eliminando así una relación con el contexto difícilmente casual. Ya se trataran de ofrendas fundacionales o apropiaciones simbólicas de depósitos anteriores, implican un recuerdo del lugar de depósito, o bien de la tecnología ritual, que indica la comprensión de las ofrendas de hacha durante la Edad del Hierro.

Pese a esa continuidad, estos ritos suponen una redefinición significativa. Mientras que en Bronce Final los depósitos se realizaban en espacios naturales, en la Edad del Hierro el lugar de ofrenda está determinado por la presencia de un castro que, o bien se apropió del espacio de un depósito anterior, o bien se vinculó con el territorio a través de uno nuevo. Han pasado de ser ritos relacionados con la interacción, a apropiaciones simbólicas del territorio; una redefinición claramente interesada a la hora de legitimar los cambios sociales provocados por el nuevo paisaje sedentario.

La relación del hacha con la deforestación posiblemente explique la continuidad de estas ofrendas en el mundo castreño. Aunque sus habitantes no tuvieran un recuerdo concreto de su importancia en los procesos de sedentarización, sí resulta posible que, derivado de ella, el útil constituyese algo más que una herramienta: un signo civilizador capaz de sintetizar el poder humano de afectar su entorno, quizás buscando que las ofrendas reprodujeran a nivel simbólico su capacidad para domesticar el paisaje (Santos Cancelas, 2017: 192194). Pese a las incógnitas, da la impresión que, frente a la desactivación simbólica de las esferas de la guerra y el prestigio aristocrático las comunidades castreñas amplificaron la importancia religiosa de la agricultura y la territorialidad, lo que se verifica en otro tipo de indicios.

\subsection{Ofrendas en los castros}

Aunque la parquedad de depósitos en los castros contrasta con su cantidad en Bronce Final, el caso de las hachas incide hasta qué punto han sido nuestras preconcepciones las que han determinado la selección de datos (Merrifield, 1987: 7 y ss.), obviando ciertos indicios y postulando como característicos ritos ausentes en el registro.

En Lagos existen una serie de campos de fosas empleadas para la obtención de xabre, que fueron clausurados como basureros, presentando un expolio muy variado. Por ello destaca un foso en el que se ha encontrado una inusual concentración de un tipo cerámico concreto, y otro caso con un recipiente cerámico intencionalmente retirado antes de romperse y clausurarse su fosa (Martins, 1988: 33-36). Aun con una correcta documentación, no se identificó en estos gestos indicios de ritualidad, pese a que este tipo de ofrendas en fosas son habituales y cuentan con paralelos en Cameixa (Parcero, 1997) 0 Neixón (González Ruibal, 2010)4 o, ya en fechas de Hierro Final, San Millán o Santo Ovidio de Fafe (González Ruibal, 2006-07: 581-582).

Este tipo de pequeñas ofrendas, invisibilizadas por la propia investigación, posiblemente constituyeran la acción ritual más habitual de esta religión. Aunque existen indicios de gestos más solemnes, sorprende su poca densidad: no suele aparecer más de uno por castro y, cuando ocurre, son poblados con una larga secuencia. Estas cuestiones perfilan una ritualidad apegada a las tareas reproductivas del grupo, con poca especialización, pero no sin complejidad, y cuya ocasión más solemne remite a la propia fundación del poblado.

4 Cameixa se dató en Bronce Final en base al arcaísmo de la forma cerámica. Sin embargo, su contexto me lleva a preguntarme si, en contra de la opinión de los arqueólogos, no podría ser castreño. Neixón, se relaciona con un supuesto intercambio púnico no exento de problemas (vid. infra). 
De Hierro Inicial proceden dos indicios interesantes de depósitos fundacionales en murallas. En Coto de Penalba, sobre un nivel de cenizas previo a la edificación de las defensas térreas, se encontró una punta de lanza de bronce arcaizante (Álvarez Nuñez, 1986). Aunque la intencionalidad del gesto no es segura, y la retirada de armas no es frecuente hasta Hierro Final -impidiendo hablar de una tendencia-, es posible que este caso presentara sentidos profilácticos, relacionados con la liminalidad del espacio y el momento, que subrayan la importancia de la muralla (vid. infra) en la definición y constitución del grupo.

El segundo caso es un hemimaxilar inferior femenino ${ }^{5}$, procedente de un nivel de cenizas previo a la construcción de la muralla de Campa de Torres (Maya, Cuesta, 2001: 62, 256-257). Un gesto excepcional que, sin embargo, no es extraño, al disponer de un posible antecedente en el cráneo femenino retirado en una cista del recinto superior de Chao en el siglo VIII a. C. (Villa, Cabo Pérez, 2003). La ocurrencia de ambos en fechas próximas podría indicar una tendencia local que, no obstante, tendría la capacidad de ilustrar fenómenos más amplios, por el hiato que plantea la aparición en Hierro Final de un fragmento mínimo de cráneo en una cista de las murallas de Palheiros (Nunes, Ribeiro, 2001). Sin embargo, mientras Chao es un depósito intencional, el caso de Campa es una mandíbula de procedencia indeterminada.

\subsection{Indicios indirectos}

Campa apunta una serie de gestos previos a la fundación de un castro que provocarían la destrucción del propio registro ritual, explicando las dificultades para su detección. No sería descabellado, a tenor de sus paralelos en Chao y Palheiros, y la aparición en Hierro Final de una iconografía de cabezas vinculada con entradas, que la mandíbula de Campa se desprendiese de un cráneo exhibido en el límite de la comunidad. Un gesto que, quizás sólo en casos excepcionales y por razones difíciles de determinar, se tradujo en la preservación de parte de los restos en casos como Palheiros.

Al mismo tiempo, los casos de Penalba y Campa ofrecen un atisbo a la importancia de la ocasión de la construcción de la muralla, cuyo carácter liminal fue examinado por Rodríguez Corral y Alfayé (2009). A su carácter defensivo -más disuasorio que ante la amenaza de destrucción- se suma su capacidad para la afirmación del grupo como lo que es, una comunidad cerrada y vinculada a su territorio. Además, su construcción implicó una redirección de esfuerzos colectivos que cohesionaría el grupo a través de la construcción de un elemento comunitario. Esto se debe relacionar con el recurso a la escisión una vez la comunidad crecía por encima de los límites prestablecidos por la muralla, pues, al fundarse el nuevo grupo siguiendo pautas similares, la construcción de las murallas articularía una forma de coherencia cultural próxima al ritual.

Esto remite a acciones que no necesariamente dejarían huella en el registro, pero que se pueden rastrear en la propia configuración de los castros. González Ruibal (2006-07: 187) ya llamó la atención sobre la escasa densidad constructiva de los castros prerromanos. Gran parte de su reducido espacio interior constituía áreas colectivas despejadas. Examinando el expolio de Torroso (Peña Santos, 1992), se aprecia un conjunto de materiales heterogéneo derivado de diversas actividades, y la ausencia de especialización del área. Por ello destaca el número de fragmentos de calderos de bronce, que si bien pudieran ser restos de fundición, indican que entre las actividades que acogía este espacio figuraban los banquetes.

La comensalidad puede constituir una importante forma de ritualidad, al ir estrechamente asociada con el sacrificio animal (Armada Pita, 2005). Evidentemente, no todas las comidas

5 Los huesos infantiles proceden de otro punto y se datan en Hierro Final. 
son celebraciones, pero la presencia de calderos de bronce en contextos castreños apunta a la solemnidad de ciertas ocasiones. Si bien su interpretación variaría enormemente en función del contexto, esa configuración abierta de los poblados prerromanos apunta más bien a un escenario de cohesión comunitaria, orientada a fortalecer los vínculos del grupo, de modo similar a las propias murallas. Ello permite valorar hallazgos de restos de caldero en grandes cabañas, como los de As Croas de Salcedo (ídem: 134), como espacios comunitarios de comensalidad $^{6}$. Escenarios que contrastan con la sofisticación de nuevas formas cerámicas y vajilla de importación -como indica la vajilla Milleflori de Tegra (Peña Santos, 1985-86: 176, 188) o las copas de bronce de Castelo de Neiva (Almeida, 1980)- a partir del siglo II a. C.

González Ruibal (2006-07: 224-225) también constató que el reducido espacio del castro se veía constreñido por la presencia de afloramientos rocosos de considerables dimensiones. Tradicionalmente se consideró el resultado natural de la elección de unos enclaves fácilmente defendibles. Sin embargo, esta característica se cumple incluso en castros en valle o próximos a la costa y, del mismo modo, la ausencia de violencia en forma de destrucción generalizada de poblados haría innecesaria una ubicación con tales condicionantes.

El autor está posiblemente en lo cierto en que esa vinculación a afloramientos rocosos buscaría entroncar con la historia del lugar y apropiarse simbólicamente del territorio ${ }^{7}$. Un argumento favorable a la interpretación de las rocas como mnemotopos serían los depósitos de Bronce Final realizados en hendiduras. No sería extraño que prevaleciese un recuerdo de esa significación entre unas comunidades castreñas necesitadas de legitimación religiosa ante el cambio de paisaje operado. Por otro lado, en fechas próximas al siglo II a. C. hay indicios de que las grandes rocas volvieron a constituir espacios para la ofrenda, como los casos de Bardaos, Riotorto, o Recadeira, en los que se retirarían varios torques (vid. infra). Y ya en Hierro Final, hay rocas -como Novás (relacionado con escenarios de comensalidad) - que se dotaron de escaleras rupestres, y en diversos castros -O Facho, Monte Mozinho, Santa Luzia- se emprenden reformas que respetan y resaltan espacios condicionados por afloramientos rocosos.

Aunque no hay indicios directos en fechas prerromanas, los datos expuestos son favorables a su importancia como lugar de culto. Más difícil es determinar su sentido, pues no es apropiado hablar de culto a las rocas. En todo caso, se puede constatar que estos grupos carecen de una noción de santuario como lugar de culto específicamente construido para acogerlo. En su lugar, los espacios del ritual están determinados por la presencia de áreas funcionales o elementos naturales, y sin segregación aparente de accesos. Es uno de los aspectos donde el contraste con Hierro Final es mayor, ante la aparición de monumentos de forno, ofrendas domésticas, o singularización de espacios de culto (Santos Cancelas, e.p.) que suponen la aparición de santuarios (vid. infra).

Frente a la definición colectiva de lo castreño explorada hasta ahora, la metalurgia plantea una fuente de desigualdad. Aunque el trabajo en bronce se orientaba al autoconsumo, el hierro requiere conocimientos específicos y un grado de especialización. Sin embargo, las áreas metalúrgicas localizadas en una serie de castros prerromanos no permiten detectar que aquella se tradujera en una diferenciación interna, basada en el conocimiento, adquisición o control de materia prima.

6 Aunque en ciertos casos se ha identificado como bancos corridos zócalos o cimientos de cabañas.

7 Aunque la vinculación que sugiere de ciertos castros con petroglifos me parece más dudosa. 
Figura 1. 1- Santa Luzia (Viana do Castelo).

2- Monte Mozinho (Penhafiel) (Cultura Norte Portugal y Camara Municipal de Penafiel)
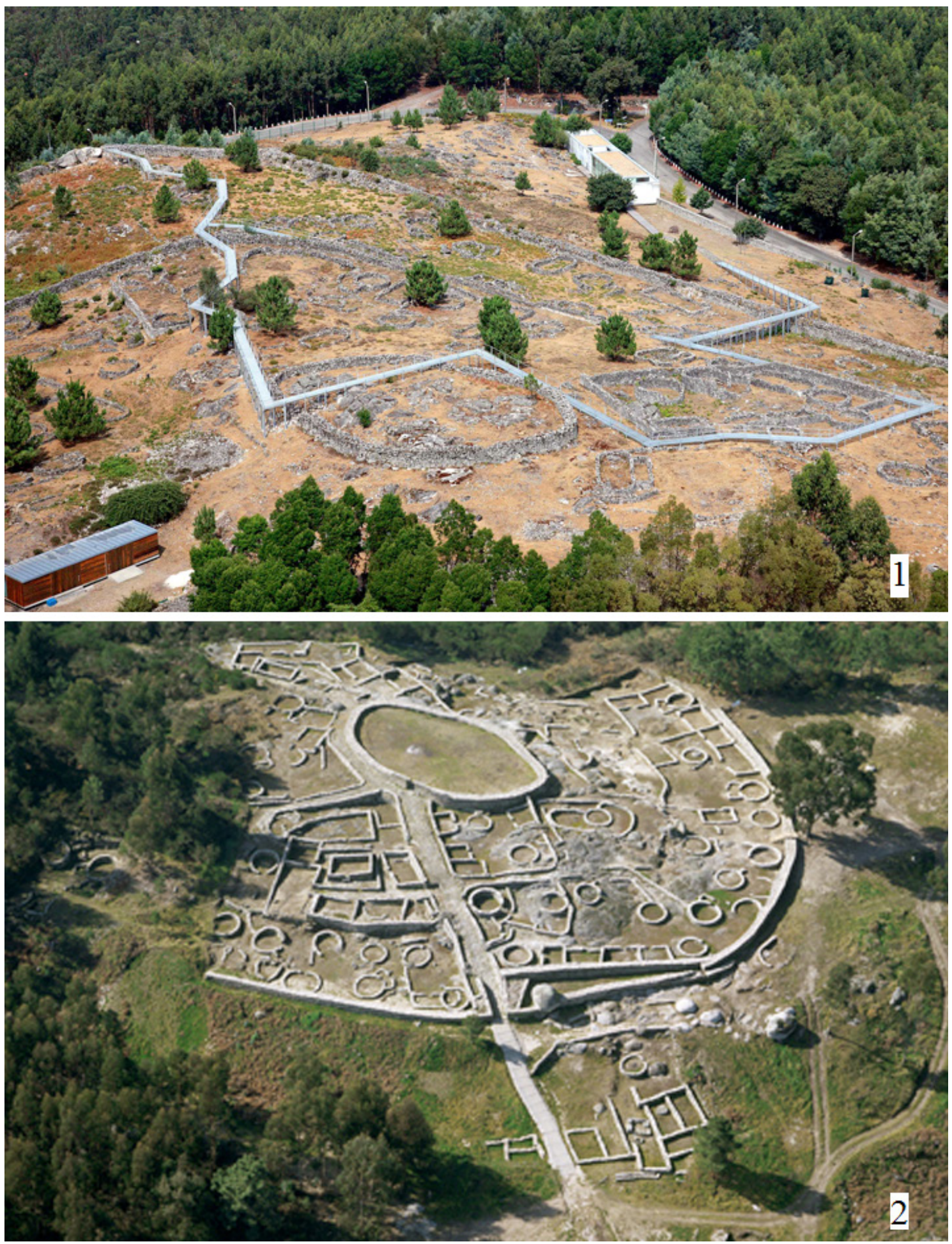

Se ha propuesto entender al herrero como un trabajador dependiente de la comunidad, cuya subsistencia garantizaba el grupo a cambio de sus servicios (Sastre, Sánchez Palencia, 2013). Esta hipótesis sospecha que el espacio del metalurgo constituyó un punto 
de reunión y socialización vinculado a los ritmos de la comunidad. Parece que entre las formas de socialización del herrero se incluiría el ritual, quizás para regular el intercambio entre el grupo y el metalurgo, un aspecto en el que la celebración pudo tener precisamente la función de prevenir la acumulación de excedentes. No parece descabellada una cierta presión social sobre el herrero para forzar el retorno de bienes en forma de festival.

El último tipo de indicios indirectos procedería de los concheiros, en los que se ha tendido a infravalorar la importancia que podría tener la ocurrencia de huesos de canidos, tales como los documentados en Montelagre (Fernández Rodríguez, 2006), o referencias tangenciales como Castro de Vigo (Hidalgo Cuñarro, 1992-1993: 42). Aunque se datan en Hierro Final, es posible que fuese un tipo de sacrificio animal en relación con espacios de riesgo/miasma cuya vigencia podría ser anterior (Santos Cancelas, 2017: 383-385). Por otro lado, los restos de ciervo, caballo, lobo o perro aparecidos en concheiros indican la práctica de caza. La mandíbula de oso descontextualizada procedente Cerca de Sejas (Esparza Arroyo 1986: 188-210) se relacionaría con esta esfera, o bien con el acceso probatorio a cuevas para la obtención de tales restos durante la hibernación del animal. Los testimonios de Hierro Final de Moñes y el bronce votivo del Instituto de Valencia de Don Juan (Armada Pita, García Vuelta, 2003: 53), señalan la importancia simbólica de ciertos animales, como principales competidores en el entorno de los castros (Alonso Burgos, 2014: 225).

Figura 2. Detalle del Oso en el bronce votivo del Instituto Valencia de Don Juan.

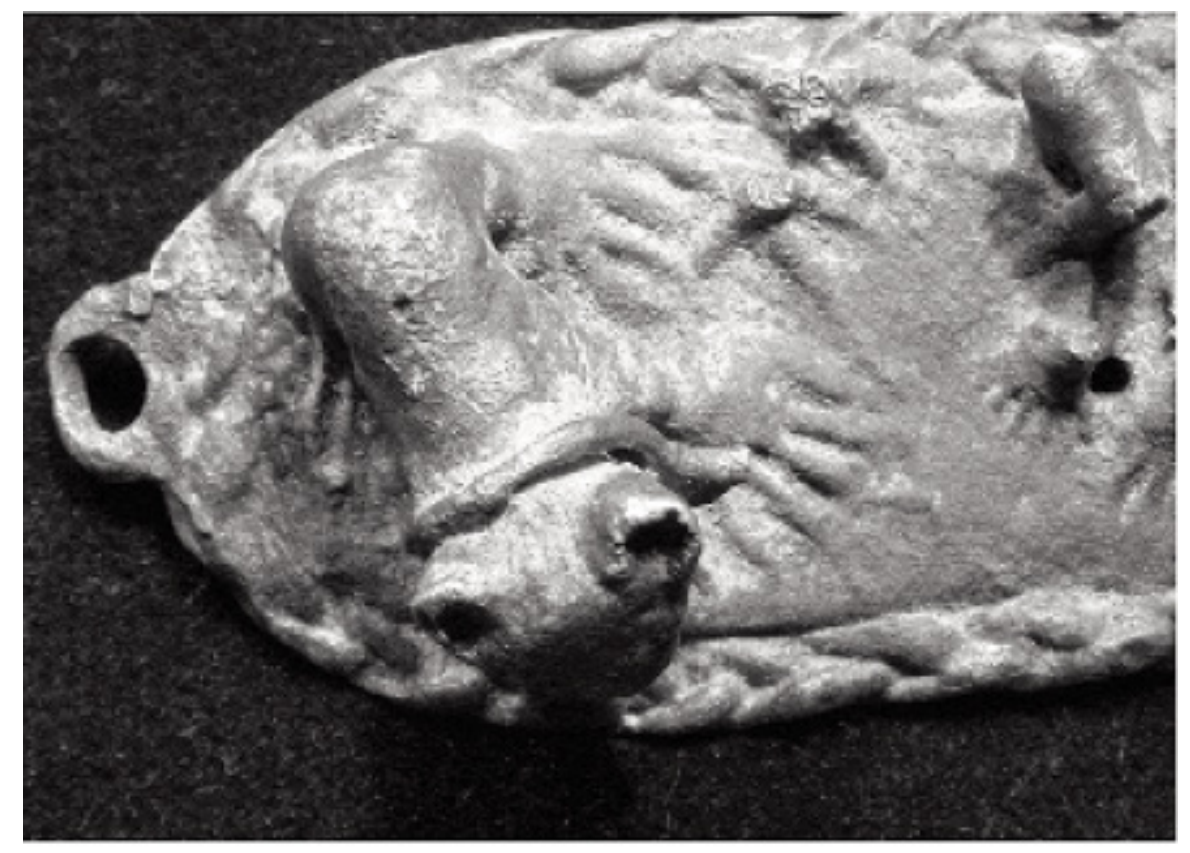

Fuente: Armada Pita y García Vuelta, 2014

En grupos como los castreños, la caza no sería una actividad deportiva vinculada al prestigio aristocrático, sino una tarea colectiva, quizás reservada a los hombres jóvenes. Ante la ausencia de importancia ritual de la guerra, la caza podría ofrecer una ocupación socializadora, en la que expresar relaciones de solidaridad o competencia en el grupo o incluso con otras comunidades. No sería incoherente que constituyese una iniciación masculina ofreciendo un espacio simbólico en el que expresar formas de dominación y prestigio basadas en el género, sin redundar en desigualdades de clase. 


\subsection{Horizonte Funerario}

El rasgo más particular de las religiones castreñas no es otro que la absoluta inexistencia de un registro funerario. Durante mucho tiempo se consideró que todavía no se había descubierto; que se debería identificar con uno u otro hallazgo; o bien que el elevado nivel de acidez del suelo habría eliminado los restos cadavéricos. Sin embargo, no se ha localizado pauta alguna susceptible de interpretarse como la gestión normativa de la muerte. Los hallazgos aislados (Bettencourt, 2001), se encuadran sistemática en Hierro Final y suponen cambios sin precedentes, al tratarse de supuestas urnas cinerarias retiradas en viviendas. Y la destrucción del registro por procesos post-deposicionales no explica la ausencia de ajuares y monumentos. Asumiendo que la no gestión del óbito no es posible, la inexistencia de este registro apunta a que el rito normativo pasaba por la destrucción intencional del cadáver y la invisibilización completa del universo de la muerte, siendo la pregunta qué gestos lo permitieron.

El caso de Campa indicaría que la mutilación postmortem, desmembración y exhibición eran acciones conocidas en el tratamiento del difunto. Ya en Hierro Final, en un afloramiento rocoso del castro de Meirás (González Ruibal, 2006-07: 579-581), se encontró la mayor muestra cadavérica de cronología castreña, con restos diversos y ningún esqueleto completo, indicando que la destrucción y selección de los restos era un hecho intencional. Quizás un posible eco de estos gestos fuese malinterpretado por Estrabón cuando se refiere a la costumbre de dejar a los enfermos en las encrucijadas para ser curados. Ante el improbable resultado de tal operación y los rasgos liminales del espacio, quizás esté describiendo un rito funerario de exposición fuera del castro, con una posible simbología iniciática de la muerte como enfermedad (Santos Cancelas, 2017: 413-418).

Por otro lado, se ha sugerido que algunos recipientes cerámicos en fosas, como los mencionados de Lagos y Cameixa, pudieran haber sido restos de incineración, si bien ninguna información certera se ha aportado en esta dirección, incluso cuando en fechas de Hierro Final disponemos de más ejemplos de este tipo procedentes de unidades domésticas -como Terroso, Ancora, Briteiros, Castromao (Santos Cancelas e.p.)-. Si tales gestos eran ritos relacionados con la fertilidad y la agricultura, no sería extraña la amortización de restos cinerarios, en un esquema de muerte y renacimiento propia de ciclos agrícolas, que en Hierro Final fue subvertida en la construcción de linajes. Ello no implicaría que se tratara del rito funerario normativo, sino que sugiere una amortización particular de los difuntos en ritos concretos, como ocurría con Campa, explicando así por qué no cumplen con la invisibilización habitual. Y teniendo en cuenta el carácter mínimo de los supuestos restos cinerarios, la desmembración e incineración no serían excluyentes y podrían estar más bien determinadas por el tipo de rito en el que se amortizarían los restos.

Es posible proponer que el rito funerario castreño buscaba la destrucción total del cadáver. La utilización de ciertos restos en ritos grupales concretos, sugiere una forma de retorno del fallecido a la comunidad. Suscribo a Alonso Burgos (2014) en que la eliminación del muerto concreto, evitaba la aparición de diferencias en el grupo -algo con lo que los casos de Hierro Final rompen-, e instituía el castro como único referente ideal de su paisaje simbólico. Si, como sugiero (Santos Cancelas, 2017: 1139-1141), las cabezas castreñas de Hierro Final pudieron ser una "petrificación ritual" de gestos excepcionales como el de Campa o Palheiros, estas supondrían una reivindicación del rito tradicional colectivo, frente a los cambios de este periodo.

\section{CAMBIOS INCIPIENTES}

Sobre lo descrito hasta este punto, en algún momento se dan una serie de cambios

que, pese a la novedad que suponen, han tendido a leerse como "característicos" de 
esta religión. Sin embargo, son manifestaciones inéditas cuyo interés subyace en cómo variaría su interpretación en función de su aparición anterior o posterior a la segunda mitad del siglo II a. C.

Por un lado estarían los torques. Pese a hundir sus raíces en tradiciones técnicas de la orfebrería del Bronce Final (García Vuelta, 2002), ninguno aparece en contextos anteriores al siglo II a. C. ${ }^{8}$. Sin embargo, un buen número de ejemplares aparecieron fuera de poblado sin relación con contextos arqueológicos definidos, de modo que, como recuerdan Armada Pita y García Vuelta (2014), no se puede descartar fechas previas para el inicio de su circulación.

Pese a esta incertidumbre, es posible constatar una generalización en el consumo de torques a partir de Hierro Final en el área septentrional y los valles fluviales meridionales. Esta se ha relacionado con la emergencia de unas élites guerreras que expresaron su poder a través del torques y se representaron en esculturas de guerreros (Santos Cancelas, 2015), lo que resulta posible ante ejemplos singularizados que pudieron requerir alguna forma de mecenazgo, o ejemplos retirados en unidades domésticas. Sin embargo, esta hipótesis ignora que tales ejemplos serían próximos al cambio de era; que en el Norte no hay indicios de ninguna élite guerrera; que la iconografía de los bronces votivos testimonia lo que parece un uso litúrgico del torques durante el sacrificio animal; así como el sorprendente número de torques hallados fuera de castros o vinculados a afloramientos rocosos en su interior.

Figura 3. Torques en bronces votivos:

1-Instituto Valencia de Don Juan. 2-Detalle. 3- Lalín. 4- Cariño

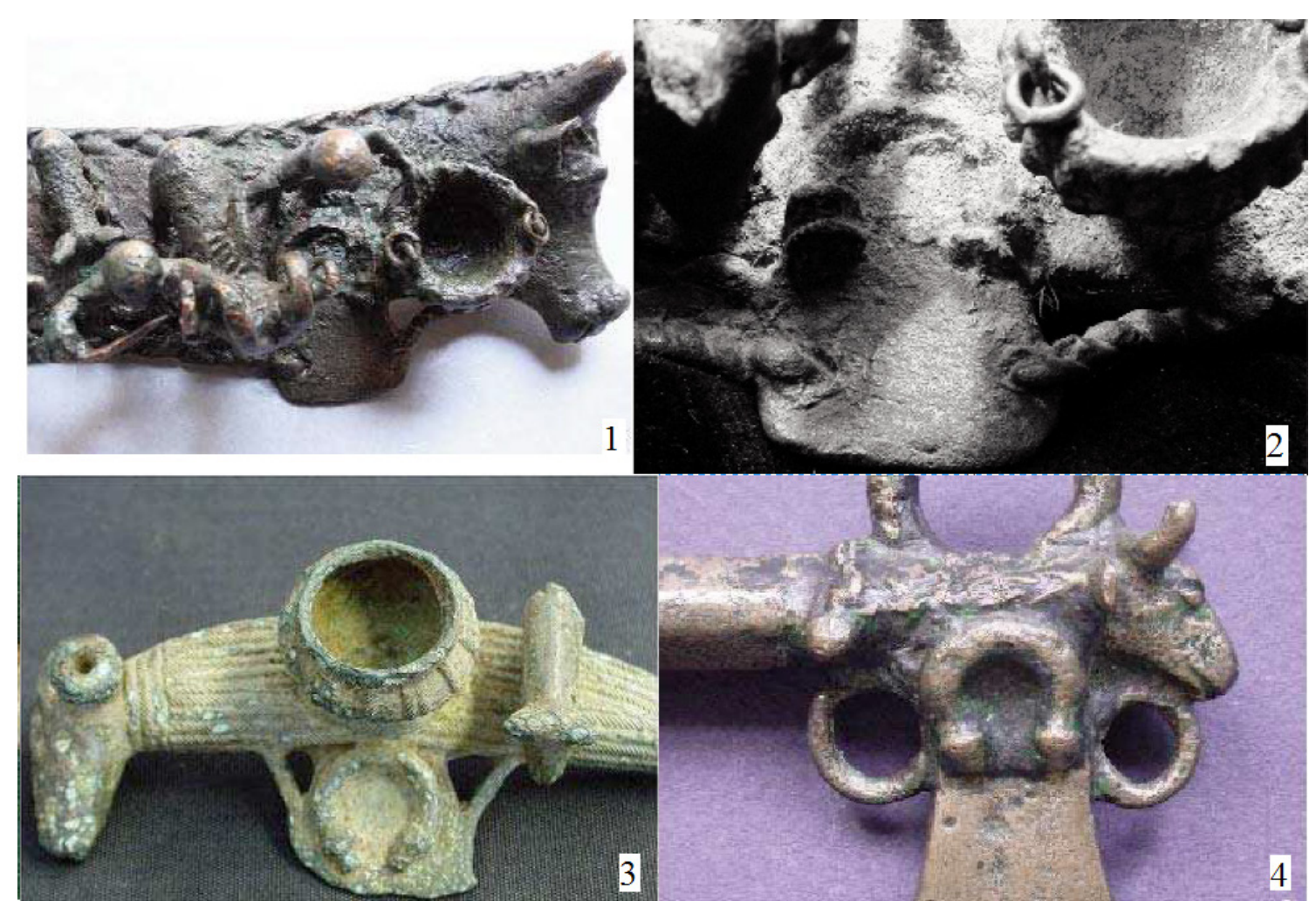

Fuente: Armada Pita y García Vuelta, 2014

La aparición reciente de conjuntos de torques fuera de poblado -caso de Vilar de Santos, a 1 km. del castro más próximo (Ladra 2005)-, o en relación a hendiduras de rocas

8 Basándose las dataciones en fechas anteriores en criterios estilísticos. 
en su interior -Bardaos (Ladra 2006)-, y la revisión de sus contextos por parte de Ladra, ha permitido constatar que tales casos no serían excepciones ni pérdidas involuntarias, sino que se trataría de depósitos intencionales. Frente a explicaciones estrictamente utilitaristas, existen abundantes paralelos en hallazgos antiguos que indican la existencia de una pauta de retirada, lo que, teniendo en cuenta la iconografía sacrificial aludida, podría indicar que los torques aparecieran como ofrendas.

Esta hipótesis, formulada por Armbruster y Perea (2000) y revisada por Armada y García Vuelta (2014), considera que los torques se originaron como ofrendas comunitarias. Por un lado, ratificando las relaciones grupales en la consecución de un elemento representativo del poder de la comunidad a través de la redirección de esfuerzos colectiva. Por otro lado, al retirarse en el exterior del castro o espacios representativos de su interior, constituirían sacrificios extremos de riqueza, que trasladarían la agencia del grupo al rito, funcionando como una compra simbólica del territorio, dirigida a la propia comunidad u otros grupos en función de su posición.

Esta interpretación trata el consumo de torques como una forma de eliminación de riqueza de la circulación orientada a prevenir su acumulación. Presentaría así una lógica coherente con relaciones productivas y ritos prerromanos, al expresar la unión de la comunidad con su paisaje. Sin embargo, al mismo tiempo es un rito que introduciría la noción de riqueza, extraña para grupos no excedentarios, así como una complejidad indeseable para prácticas que se caracterizaban por su falta de especialización.

La aparición de las ofrendas de torques manifiesta un intento por integrar en las relaciones socio-reproductivas castreñas importantes cambios sociales a través del ritual y la religión. Ello permite vincular su aparición a los acontecimientos que desde finales del siglo III a. C. azotaron la península ibérica y que, ya fuera en forma de demanda de materias primas o bien presión territorial por parte de otras comunidades paleohispánicas, afectaron también al Noroeste. Ello explicaría tanto el origen de una expresión que, pese a ser profundamente local, es contraria a las tradiciones previas, como la necesidad de ritos de afirmación más conspicuos orientados a la eliminación de riqueza. Se trata por ello de ritos que tratan de gestionar cambios derivados de un momento que, con las debidas precauciones, se podría denominar como "precolonial", pero cuyo sentido cambió ya en fechas de Hierro Final, como manifiesta la apropiación que hicieron del signo ciertas élites guerreras.

La segunda novedad también tendría que ver con cambios derivados de la interacción del Noroeste con otros horizontes, y nuevamente su interpretación variaría en función de su datación. Se trata de la aparición de betilos en Toralla y Alcabre, que se han interpretado como espacios de culto mediterráneos vinculados a la llegada de navegantes púnicos que, desde los trabajos de González Ruibal (2006-2007: 267-268), se fecha entre los siglos IV-III a. C. El problema de estas interpretaciones es que a través de este contacto se sugiere la existencia de un potente comercio prerromano que favorece la aparición de un "desarrollo" local cuyos cambios, sin embargo, no se aprecian hasta fechas de contacto con Roma.

Si bien es cierto que existen una serie de materiales de importación prerromanos -particularmente cuentas de pasta vítrea y cerámica de barnices negros-, una cuestión llamativa es su dispersión y escasa densidad por yacimiento, que contrasta con la cantidad de ánforas -púnicas y romanas- que aparecen en castros de Hierro Final. Considero que Currás (2015: 264 y ss.) tiene razón al cuestionar el empleo de conceptos como emporia aplicados a los contextos prerromanos de castros como Neixón y A Lanzada. Los niveles de reforma en los que aparecen estructuras como la supuesta factoría de salazón púnica de este último se han datado a través del límite post quem de materiales con cronologías que alcanzan el cambio de era. Da la sensación de que se ha magnificado un supuesto contacto púnico prerromano para minimizar el impacto que el contacto con Roma de hecho sí supone a partir del siglo II a. C. 
Esto se aplica a los propios betilos. De los dos de Toralla, uno fue encontrado reaprovechado como material de construcción en una cabaña de finales del siglo I a. C., mientras que el otro apareció in situ ${ }^{9}$. Ello indica un contexto de uso en el entorno del siglo II a. C., coherente con ese momento que para los torques se definió como "precolonial" en relación con los acontecimientos acaecidos en la península entre finales del siglo III a. C. e inicios del II, lo que cuestiona su interpretación como santuarios púnicos.

Figura 4. Excavación arqueológica de la parcela número 24 del Castro de la Isla de Toralla

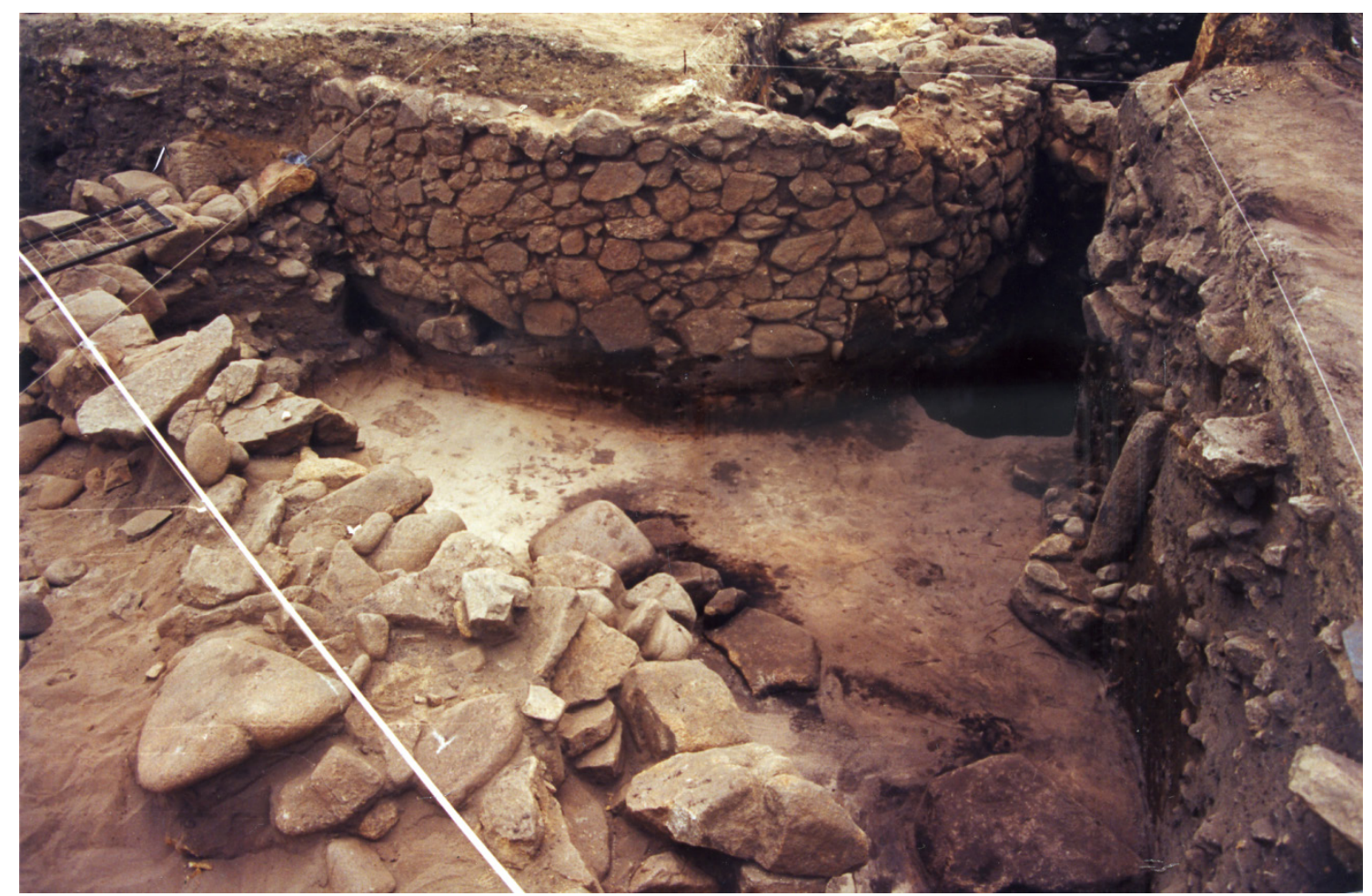

Fuente: Director Emilio Abad Vidal Grupo de Estudos para a Prehistoria do NW Ibérico-Arqueoloxía, Antigüidade e Territorio GEPN-AAT. Universidade de Santiago de Compostela

El caso de Alcabre, en el que tres betilos aparecieron en un fondo de cabaña castreña, indica la realización de libaciones. Se trata de un culto a las rocas a través de ofrendas humildes que, por ello, plantea continuidades con pautas tradicionales. Pero son más importantes las novedades que introduce, pues supone la aparición de los primeros espacios de culto castreños singularizados a través de elementos votivos concretos. Esta especialización del contexto ritual supone una ruptura con lo anterior, al instituir una segregación física y conceptual entre el culto y la comunidad que, por primera vez, ya no se solapan. Una diferencia que se generalizará a partir de Hierro Final con la proliferación de nuevos espacios del ritual, entre los que es elocuente la segregación que establecen las pedras formosas de las saunas meridionales.

El interés de estos betilos es que suponen la aparición de cultos anicónicos, anteriores o inmediatamente previos a la generalización de la plástica castreña y el surgimiento de espacios rituales monumentales. Explicarlos como santuarios púnicos es una explicación ex oriente lux, que disimula su enorme complejidad. Aun admitiendo que el culto a betilos pudiera ser una influencia mediterránea u oriental -quizás portada por interlocutores del círculo del estrecho, donde se constatan tales formas de culto-, su integración en

9 Según comunicación personal con Abad Vidal, a quien agradezco su colaboración y gentileza. 
espacios castreños debe entenderse como una asimilación dentro de tradiciones locales. Independientemente de los posibles sentidos religiosos que pudieran haber incorporado desde su contexto de origen, se deben explicar en relación con las tradiciones previas: el culto a las piedras, las formas de ofrenda, y las connotaciones que su carácter erecto pudiera presentar con iconografías fálicas posteriores.

Figura 5. Ídolo Elviña

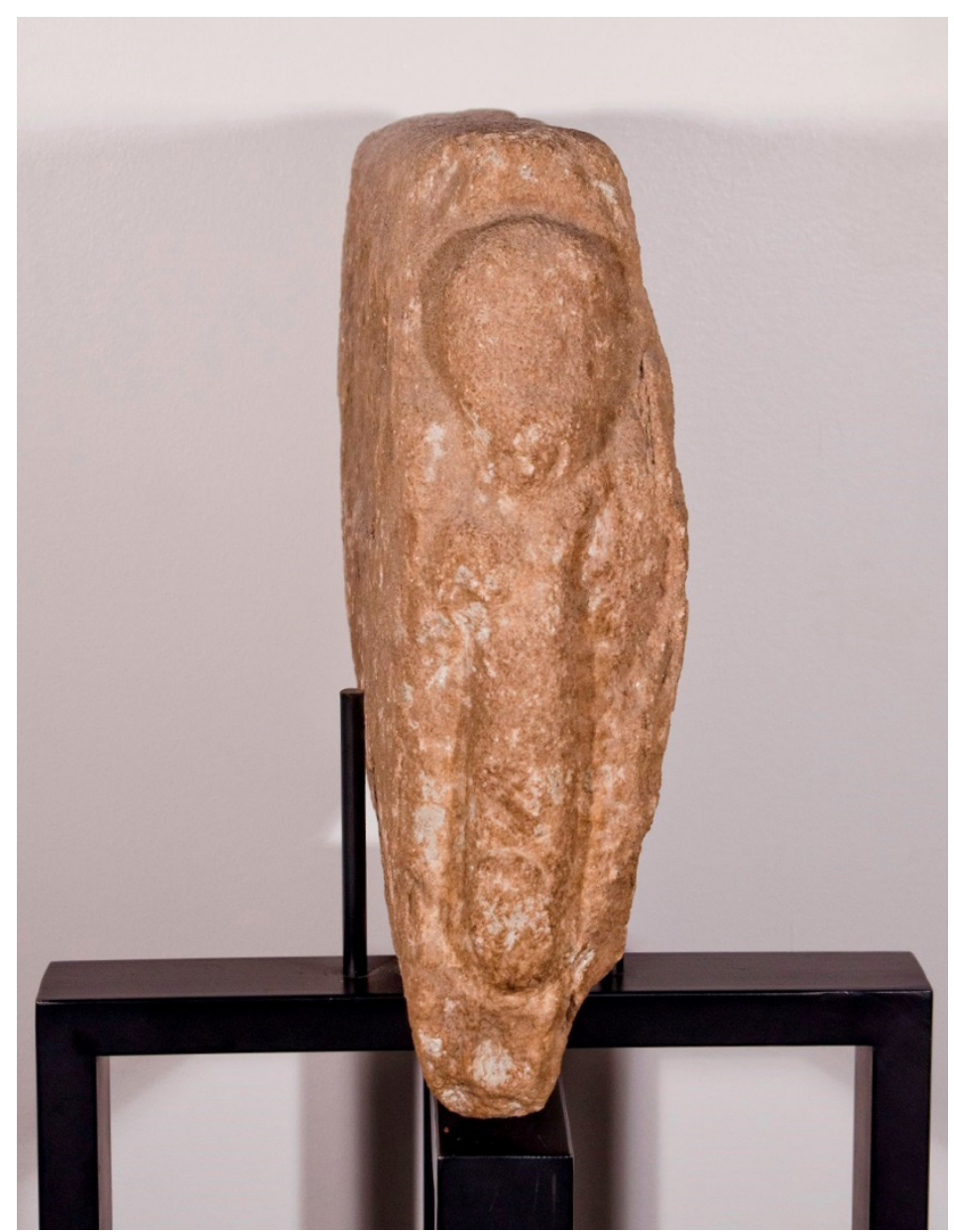

Fuente: Museo Arqueolóxico e Histórico Castelo de San Antón, A Coruña

La aparición de torques y espacios de culto supone unos cambios con respecto a las ritualidades castreñas anteriores al siglo II a. C. en relación con un contexto histórico determinado. Se trata de reacciones locales frente a un creciente entanglement con otros grupos y pueblos que, ya a partir del siglo II a. C., derivará en unas manifestaciones indígenas muy elocuentes, pero que marcan el fin de las religiones prerromanas.

\section{CONCLUSIONES: RELIGIONES ANARQUISTAS}

Estas cuestiones permiten trazar una semblanza mínima de las religiones castreñas entre el siglo VIII y el siglo II a. C.

El componente tópico adquiere una dimensión fundamental en el universo ideológico de poblaciones que buscaron establecer una estrecha asociación entre el territorio, la comunidad y el castro, a través sus murallas, ofrendas y vinculación con hitos significados de su territorio. La eliminación del horizonte funerario realzaba al castro como único elemento de su paisaje ideal, dando una idea de su poder como signo de la unión entre el grupo y su entorno. 
No es posible plantear cómo articularon esta sobredimensión del elemento tópico. Aunque hitos naturales como las rocas y nociones relativas a la fertilidad (y la agricultura) debieron ser relevantes, no parece adecuado sucumbir a la tentación de explicarlos a través de categorías de religiones mejor conocidas. Aunque es posible suponer que la comunidad trazaría algún tipo de genealogía entre ella, el pasado del lugar y el propio castro, a este esquema podrían responder nociones como divinidades, héroes, o antepasados.

Resulta difícil reconciliar con este fuerte componente tópico la idea, muchas veces sostenida a partir de la teonimia indígena consignada en epigrafía provincial, de la existencia de un panteón estructurado para el conjunto del Noroeste. Aunque hasta cierto punto fuese un sistema de tradiciones y prácticas más o menos compartido, ello no prueba su identidad. Si bien es cierto que alguna forma de relación tuvo que existir para articular las relaciones entre castros en cuestiones nada despreciables como el matrimonio, la fundación de una nueva comunidad, o solventar disputas antes de resultar en conflicto, estas no se traducen en elementos o espacios de culto regionales discernibles en el registro. No hay un sentido de reconocimiento religioso que cristalizase en algo similar a identidades étnicas. El castro lo domina todo.

Aunque podamos asumir que ciertas comunidades tendrían creencias parecidas, sobre todo entre grupos emparentados o generados a partir de otro, la noción de panteón es extraña a ellas. Un panteón solo puede ser generado en paralelo a procesos políticos con capacidad de negociar interpretaciones hegemónicas, algo imposible en comunidades sin estado. Ambas, extrañas para el Noroeste prerromano, en cambio, tienen perfecto sentido en el contexto del Imperio, como medio para asimilar realidades locales.

Por el contrario, los ritos y formas de culto examinadas se relacionan estrechamente con las actividades reproductivas del grupo. Incluso ejemplos más solemnes plantean un retorno a la comunidad y un énfasis en lo colectivo, contrario a la existencia de jerarquización, especialización religiosa o competitividad guerrera. La ritualidad castreña responde a la intencionalidad social de prevenir la aparición de fuertes desigualdades de clase en el seno del grupo.

La ausencia de especialización ritual parece obedecer la voluntad de evitar la aparición de agentes religiosos que se apropiasen de tal esfera de poder. La única excepción la constituía el herrero, y con él se apreciaba cómo la celebración impedía que su actividad se tradujese en fuente de poder. Quizás se podría hablar de una "agencia ritual distribuida" entre las intersecciones del grupo, siendo posible que la transmisión de la tradición y su interpretación se reservase a los ancianos. El argumento principal para esta hipótesis estaría en la neutralización de la relevancia simbólica de la guerra que limitaría la capacidad de la juventud para negociar su posición en el grupo. Sería esta una estructura gerontocrática (Gledhill, 2000: 37-38), que no redundaría en la capacidad de los ancianos para imponer su voluntad sobre el colectivo, al no tener autoridad sobre espacios simbólicos como la metalurgia o la caza.

Estas cuestiones plantean un escenario de una tremenda complejidad social, que no se tradujo hasta el contacto con pueblos mediterráneos en la aparición de complejidad política. La voluntad de autonomía a través de la limitación, la importancia de reciprocidad basada en la dependencia y la existencia de autoridades naturales, permiten apuntar que estas religiones se opusieron activamente a la aparición de formas de poder artificial. Se caracterizan así como "religiones contrarias al estado", al funcionar según conceptos propios de la teoría anarquista (Angelbeck y Grier, 2012), más útiles para definir estos pueblos como lo que son, en lugar de lo que carecen desde categorías ajenas a ellos. Termino ya, señalando que si bien este caso no sería una norma, tampoco fue una excepción, invitando a desafiar nuestras preconcepciones sobre el poder, la religión y la jerarquía. 


\section{BIBLIOGRAFÍA}

Almeida, C. A. F. (1980) "Dois Capacetes e tres copos, em Bronze, de Castelo de Neiva", Gallaecia, 6, 245-257.

Alonso Burgos, F. (2014): Estructura social y paisaje simbólico: las comunidades astures y el imperio romano. Tesis doctoral inédita, Universidad Complutense de Madrid.

Angelbeck, B. y Grier, C. (2012):"Anarchism and the Archaeology of Anarchic Societies Resistance to Centralization in the Coast Salish Region of the Pacific Northwest Coast", Current Anthropology 53(5): 547-587.

Armbruster, B. R. y Perea, A. (2000) "Macizo/hueco, soldado/fundido, morfología/tecnología, el ámbito tecnológico castreño a través de los torques con remates de doble escocia", Trabajos de Prehistoria, 57 (1), 97-114.

Álvarez Núñez, A. (1986): "Castro de Penalba. Campaña de 1986", Arqueoloxía, Memorias, 4.

Armada Pita, X. L. (2005) Formas y rituales de banquete en la Hispania Indoeuropea. Tesis Doctoral Inédita, Universidade da Coruña.

Armada Pita, X. L. y García Vuelta, O. (2003): "Bronces con motivos de sacrificio del área noroccidental de la península ibérica", Archivo español de arqueología, 76, 47-75.

- (2014): "Os Atributos do Guerreiro. As Ofrendas da Comunidade. Interpretación dos torques a través da iconografía", Cátedra, revista Eumesa de Estudios, Monografía, 3, 57-92.

Bettencourt, A. M. S. (2001) "O Mundo Funerario da Idade do Ferro do Norte de Portual: algumas questões", Proto-história da Península Ibérica. Actas do $3^{\circ}$ Congresso de Arqueología Peninsular, 5, pp. 43-61.

Blas Cortina, M. A. (1983): "La prehistoria reciente de Asturias", Estudios de arqueología Asturiana, 1.

Blas Cortina, M. A. y Villa Valdés, A. (2007): "La presencia no accidental de un Hacha de talón en un fondo de hogar en el castro de Chao de Samartín (Grandas de Salime, Asturias)", en Celis Sánchez, J., Delibes de Castro, G., Fernández Manzano, J. y Grau Lobo, L. El hallazgo leonés de Valdevimbre y los depósitos del Bronce Final Atlántico en la península Ibérica, León, Diputación de León, 280-289.

Brück, J. y Fotijn, D (2003) "The myth of the chief: prestige goods, power, and personhood, in the European Bronze Age", The Oxford Handbook of the European Bronze Age. Oxford University Press. Oxford, 197-205.

Carballo Arceo, X. y Rey Castiñeiras, J. (2014): "O depósito de Máchados de talón de Cabeiras (Arbo, Galiza) no contexto da Bacia Baixa do río Miño", en Bettencourt, A. M. S., Comendador Rey, B. y Aluai Sampaio, H., Corpos e metáis na fachada atlántica da Iberia. Do Neolítico a Idade do Bronze. Braga, Citcem, 103-120.

Clastres, P. (1984), Socity Against the State, New York, Zone books.

Currás, B (2014): Transformaciones sociales y territoriales en el Baixo Miño entre la Edad del Hierro y la integración en el Imperio Romano, Tesis doctoral inédita, Universidad de Santiago de Compostela.

Esparza Arroyo, A. (1986) Los castros de la Edad del hierro del Noroeste de Zamora. Zamora: Instituto de Estudios Zamoranos de Florian de Ocampo.

Fabian, J. (1983): Time and the Other. How anthropology makes its object, Columbia.

Fanjul Peraza, A. y Marón SUÁREZ, C. (2006): "La metalurgia del Hierro en la Asturias Castreña. Nuevos datos y estado de la cuestión”, Trabajos de Prehistoria, 63, 113-131.

Fernández Rodríguez, C. (2006): "Os recursos de orixe animal: primeiros datos e avaliación preliminar", en Aboal Fernández, R. y Castro Hierro, V. (coords.), O Castro de Montealegre, Moaña, Pontevedra, Noia, Toxosoutos, 325-340. 
García Quintela, M. V. (1999): Mitología y mitos de la Hispania prerromana III. Madrid: Akal. García Vuelta, O. (2002) "Técnicas y evolución, fabricación y materias primas en los torques", en Rodero Riaza, A. y Barril Vicente, M. (coords.), Torques. Belleza y poder. Madrid, Museo Arqueológico Nacional, 31-47.

González García, F. J. (2006): "El noroeste de la península ibérica en la Edad del Hierro: ¿una sociedad pacífica?”, Cuaderno de Estudios Gallegos, 53 (119), 131-155.

González García, F. J., Parcero, C., Ayán Vila, X. (2011): "Iron Age societies against the state. An account on the emergence of the Iron Age in the NW Iberian Peninsula". en T. Moore y X. L. Armada Pita (eds.): Atlantic Europe in the first Millenium BC. Crossing the Divide, Oxford, Oxbow books, 285-262

González Ruibal, A. (2006-07): "Galaicos, poder y comunidad en el Noroeste de la Península Ibérica (1200 a.C.-50 d.C.)" Brigantium boletín do museo arqueolóxico da Coruña, 18-19.

González Ruibal, A., Rodríguez Martínez, R. y Ayán Vila, X. (2010): "Encounters in the ditch: ritual and middle ground in an Iron Age hillfort in Galicia (Spain)", Bolletino di archeologia on line, volume special, 25-31.

Gledhill, J. (2000): Power and its desguises, Anthropological Perspectives on Politics, London, Pluto Press.

Hidalgo Cuñarro, J. M. (1992-1993): "Nuevas cerámicas romanas de importación del Castro de Vigo (Campaña de 1987)", Castrelos, 5-6, 41-70.

Hingley, R. (2009): "Esoteric knowledge? Ancient Bronze Artifacts from Iron Age Contexts", Proceedings of Prehistoric Society, 75, 143-165

Ladra, L. (2005): "Dous novos torques achados en Vilar do Monte (San Fiz de Reimondez, Sarria, Lugo)", Anuario Brigantino, 28, 27-38.

- (2006) "Un novo torques achado na croa de Bardaos (Tordoia, A Coruña)", Anuario Brigantino, 29, 39-52.

Martin, M. (1988): "O povoado fortificado de Lagos, Amares", Cadernos de Arqueología, Monografías, 1.

Maya, J. L y Cuesta, F. (2001): "Excavaciones arqueológicas y estudio de los materiales de La Campa de Torres", en Maya González, J. L y Cuesta Toribio, F. (dirs.), El Castro de la Campa de Torres. Periodo Prerromano. Gijón, Ayuntamiento de Gijón, 11-277.

Meijide Cameselle, G. y Acuña Castroviejo, F. (1989): "Piezas de la Edad del Bronce en el Museo de la Tierra de Melide", Cuaderno de Estudios Gallegos, 28 (103), 7-34.

Merrifield, R. (1987): The Archaeology of ritual and magic, London, Routledge.

Nunes, S. A., y Ribeiro, R. A. (2001): "Uma estrutura funeraria da Idade do Ferro em contexto habitacional no castro de Palheiros - Murça NE de Portugal", Protohistória da Península Ibérica. Actas do $3^{\circ}$ Congresso de Arqueología Peninsular, 5, 23-43.

Parcero Oubiña, C. (1997): "Documentación de un entorno castreño: Trabajos Arqueológicos en el Área de Cameixa, Ourense", Trabajos en arqueología del paisaje, 1, 2-26.

Parcero Oubiña, C., Ayán Vila, X., Fábrega Álvarez, P. y Teira Brión, A. (2007): "Arqueología, paisaje y sociedad", en González García, J. (coord.), Los pueblos de la Galicia céltica, Madrid: Akal, 131-257.

Parcero Oubiña, C. y Criado Boado, F. (2013): "Social change, social resistance. A long term approach to the process of transformation of social landscapes in the NW Iberian Peninsula", en Cruz Berrocal, M., García Sanjuán, L. y Gilman, A. (coords.), The Prehistory of Iberia: Debating Early Social Stratification and the State. London: Routledge, 249-266.

Peña Santos, A. de la (1985-86): "Tres años de excavaciones arqueológicas en el yacimiento galaico-romano de Santa Tegra (A Guarda, Pontevedra)", Pontevedra Arqueológica, 2, 157-189. 
- (1992): Castro de Torroso (Mos, Pontevedra). Síntesis de las memorias de las Campañas de excavaciones 1984- 1990, Santiago de Compostela, Xunta de Galicia.

Quesada Sanz, F. (1997): El armamento Ibérico. Estudio tipológico, geográfico, funcional, social y simbólico de las armas en la Cultura Ibérica (Siglos VI-I a.C.), Montagnac, Éditions Monique Mergoil.

Rodríguez Corral, J. y Alfayé, S. (2009): "Espacios liminales y prácticas rituales en el noroeste peninsular", Actas de paleohispánica, 9, 107-111.

Ruíz-Gálvez Priego, M. L. (1980): "Consideraciones sobre el origen de los puñales de antenas gallego-asturianos", Actas do seminario de arqueología do Noroeste peninsular, 1, 85-112.

Santos Cancelas, A. (2015): "La memoria de las piedras. El pasado presente en los guerreiros Castreños", Antesteria, 4, 167-186.

- (2016b): "Muchas teorías y pocas fuentes: religiones castreñas", en Cisneros, I., Herrera, J. y Lanau, P. (eds.), Problemas y limitaciones en el estudio de las fuentes. Actas de las I jornadas doctorales en Ciencias de la Antigüedad, Zaragoza 18 de Septiembre de 2015, 15-28.

- (2017) Ritos, memoria e identidades Castreñas, Tesis doctoral inédita, Universidad de Zaragoza.

- (e.p.): "Cambio Cultural e hibridación religiosa: el caso castreño", Archivo Español de Arqueología.

Sastre, I. (2011): "Social inequality during the Iron Age: Interpretation Models", en T. Moore and X. L. Armada Pita (eds.): Atlantic Europe in the first Millenium BC. Crossing the Divide, Oxford, Oxford University Press, 264-284.

- (2008): "Community, identity and conflict. Iron Age Warfare in Iberian Northwest", Current Antropology 49, 1021-1051.

Sastre, I. y Sánchez Palencia, F. J. (2013): "Non-hierarchical approaches to The Iron Age societies: Metals and inequality in the Castro Culture of The Northwestern Iberian Peninsula", en M. Cruz Berrocal, L. García-Sanjuán, y A. Gilman (eds.): The Prehistory of Iberia. Debating social stratification and the State, London, Routledge 292-310.

Suárez Otero, J. (2007): "Hachas de talón decoradas: un fósil de la ritualidad en torno a la producción metalúrgica del Bronce Final Atlántico", en Celis Sánchez, J., Delibes de Castro, G., Fernández Manzano, J. y Grau Lobo, L. (eds.), El hallazgo leonés de Valdevimbre y los depósitos del Bronce Final Atlántico en la península Ibérica, León, Diputación de León, 290-297.

Villa Valdés, A. y Cabo Pérez, L. (2003): "Deposito funerario y recinto fortificado de la Edad del Bronce en el castro de Chao de Samartín: Argumento para su datación", Trabajos de prehistoria, 60 (2), 143-151.

Woolf, G. (2011): Tales of the barbarians: ethnography and the empire in the Roman West, Sussex, Wiley-Blackwell. 